\title{
Functional diversity and coexistence of carnivorous and noncarnivorous plants in wet, species-rich savannas
}

\author{
Stephen Brewer ${ }^{1}$ and Peter Zee ${ }^{1}$ \\ ${ }^{1}$ University of Mississippi
}

February 23, 2021

\begin{abstract}
1. Trait differences among plant species can favor species coexistence. The role that such differences play in the assembly of diverse plant communities maintained by frequent fires remains unresolved. This lack of resolution results in part from the possibility that species with similar traits may coexist because none has a significant fitness advantage and in part from the difficulty of experimental manipulation of highly diverse assemblages dominated by perennial species. 2. We examined a 65-year chronosequence of losses of herbaceous species following fire suppression (and subsequent encroachment by Pinus elliottii) in three wet longleaf pine savannas. We used cluster analysis, similarity profile permutation tests and k-R cluster analysis to identify statistically significant functional groups. We then used randomization tests to determine if the absence of functional groups near pines was greater (or less) than expected by chance. We also tested whether tolerant and sensitive species were less (or more) likely to co-occur by chance in areas in savannas away from pines in accordance with predictions of modern coexistence theory. 3. Functional group richness near pines was lower than expected from random species extirpations. Wetland perennials with thick rhizomes and high leaf water content, spring-flowering wetland forbs (including Drosera tracyi), orchids, Polygala spp., and club mosses were more likely to be absent near pines than expected by chance. C3 grasses and sedges with seed banks and tall, fall-flowering C4 grasses were less likely to be absent near pines than expected by chance. Species sensitive to pine encroachment were more likely to co-occur with other such species away from pines at two of the three sites. 4. Results suggest that herb species diversity in frequently-burned wet savannas is maintained in part by a weak fitness (e.g., competitive) hierarchy among herbs, and not as a result of trait differences among co-occurring species.
\end{abstract}

\section{Hosted file}

Revised manuscript 12-16-2020.docx available at https://authorea.com/users/397532/articles/ 510378-functional-diversity-and-coexistence-of-carnivorous-and-noncarnivorous-plants-inwet-species-rich-savannas 